\title{
Preconditioning exposure to contextual cues and the acquisition of the keypeck behavior in autoshaping by pigeons
}

\author{
MAURICIO PAPINI, DANIEL LINWICK, and J. BRUCE OVERMIER \\ University of Minnesota, Minneapolis, Minnesota
}

\begin{abstract}
Acquisition of classically conditioned responses has been described as a direct function of the interreinforcer cycle, $\mathrm{C}$, and an inverse function of signal duration, $\mathrm{T}$. There is no agreement as to whether $\mathrm{C}$ is the interreinforcer mean interval or the session length divided by the number of reinforcements given. This issue was studied in an experiment with three groups of pigeons receiving different presession adaptation periods. The birds were placed in the conditioning box for 30,300 , or 3,000 sec before the first daily training trial. Birds in Group 30 showed significant impairment in acquisition rate; the performances of Groups 300 and 3,000 were not different from each other. Because the greatest impact of this manipulation was expected between $\mathbf{3 0 0}$ and 3,000 sec-where no differences were found-the results were not consistent with the hypothesis that pigeons start "computation" of C as soon as they are placed in the conditioning apparatus.
\end{abstract}

Gibbon, Farrell, Locurto, Duncan, and Terrace (1980) presented evidence from a variety of experiments on Pavlovian conditioning that the partial reinforcement acquisition effect is eliminated if acquisition is plotted as a function of reinforcements instead of a function of trials. Gibbon and Balsam (1981; see also Balsam, 1984) interpreted these results using the scalar expectancy theory (SET) of conditioning, which assumes that the animal compares the expectancy associated to the context with that associated to the signal. Contextual expectancy is assumed to be an inverse function of the interreinforcer cycle time (C), and signal expectancy an inverse function of signal duration (T). According to SET, acquisition is modulated by these variables and is a function of an expectancy ratio, $\mathrm{C} / \mathrm{T}$. The greater the expectancy ratio is, the faster the acquisition of the conditioned response.

Although the computation of the $\mathrm{C} / \mathrm{T}$ ratio incorporates specifically the interreinforcer times, researchers disagree about the importance, if any, of the waiting time in the apparatus before the delivery of the first reinforcer-the so-called preconditioning (sometimes called "presession') adaptation period. The question is whether the $C$ value is the interreinforcer mean interval or the total session length divided by the number of reinforcers given. If the preconditioning period before the first reinforcer is equal to the interreinforcer interval, then the two computations are equal; however, if the preconditioning period is different (i.e., longer), they diverge. Jenkins, Barnes,

This research was supported by grants to J. B. Overmier and to the Center for Research in Human Learning. M. R. Papini was supported by a grant from Consejo Nacional de Investigaciones Científicas y Técnicas, Argentina. His present address is: Facultad de Psicología, Universidad de Buenos Aires, Av. Independencia 3065, 1225-Buenos Aires, Argentina. Requests for reprints should be sent to J. B. Overmier, Department of Psychology, University of Minnesota, Elliott Hall, Minneapolis, MN 55455. and Barrera (1981) addressed this question and briefly reported (Experiment 5$)$ that a long wait $(100 \mathrm{~min})$ before the first daily trial did not improve acquisition; indeed a smaller percentage of those in the long-wait group attained the learning criterion.

Several recent experiments have suggested that a discrete stimulus will be timed if it has excitatory value through prior pairings with an unconditioned stimulus (US) (Roberts \& Holder, 1984, 1985). These results suggest that since the context has usually been paired with food during magazine training, the adaptation period should be included in the computation of $\mathrm{C}$, as does the assumption that discrete and contextual stimuli are functionally equivalent (e.g., Balsam, 1985). Expectations based on these two views contrast with the Jenkins et al. (1981) result. Therefore, this issue deserves additional attention.

This issue merits attention on another basis as well. Papini and Overmier (1984) found no differences between a continuous-reinforcement and two different partialreinforcement (PRF) groups, all with equal C/T ratios, when acquisition was considered as a function of reinforcers; however, acquisition speed was a function of the number of trials per session in each condition. Differences in this variable arise in PRF experiments if, as usual, the number of reinforcements per session is held constant. Because variations in the number of trials per session lead to different session lengths, the effect reported by Papini and Overmier could be attributed either to differences in the number of trials per session or to different total session lengths. But more important for the present issue, they used a constant 5-min adaptation period at the start of each session. Because of differences in the number of trials per session and number of sessions between groups, both the total and the relative duration of the preconditioning adaptation time also differed across groups and 
might have contributed to group differences. This example makes clear that the issue of preconditioning adaptation times now needs to be addressed directly, unconfounded with PRF variations and/or numbers of trials per session.

To evaluate the effect of length of preconditioning adaptation periods independently of number of trials, adaptation periods of different lengths across groups were used in the experiment reported here, with the number of following conditioning trials held constant. If computation of $\mathrm{C}$ is initiated with the first reinforcement, no differences between groups should be observed. On the other hand, if $\mathbf{C}$ is a function of the complete duration of the session including the preconditioning adaptation, differences between groups can be predicted following a simple rule: the longer the adaptation period (and hence, $\mathrm{C}$ ), the smaller the expectancy accrued to the context, and therefore the faster the rate of acquisition to the signal.

\section{METHOD}

\section{Subjects}

Fifteen naive pigeons were used. They were housed in individual cages with continuous illumination. Although water was freely available, the subjects were deprived of food until they reached $80 \% \pm 4 \%$ of their free-feeding weights. Additional amounts of food were provided at least 20 min after the end of each training session so as to maintain the target weights.

\section{Apparatus}

Three similar boxes (Coulbourn Instruments, Inc.) were used. Internal measurements of the boxes were 32.5 (height) $\times 24.1$ (width) $\times$ $29.5 \mathrm{~cm}$ (length). A ceiling lamp provided diffuse illumination throughout the session. A key $(2.5 \mathrm{~cm}$ in diameter) was located in the center of the front wall, approximately $20 \mathrm{~cm}$ above the floor. During a trial, the key was illuminated from behind with a green light; during the intertrial interval (ITI), the key was dark. A hopper was placed at one side of the key, approximately $11 \mathrm{~cm}$ above the floor. A speaker located in the upper right corner of the front wall provided constant white noise, which, together with the fan, achieved a level of about $80 \mathrm{~dB}$ (SPL, Scale B). Each box was enclosed in a sound-reducing cubicle.

\section{Procedure}

The pigeons received three sessions of magazine training. In the first session, they had free access to the hopper until they were observed to eat for 3 to $5 \mathrm{~min}$. Afterward, they received 2010 -sec presentations of the hopper (the US), separated by a 24-sec interval. In the second and third sessions, the subjects received 203 -sec US presentations with a 24-sec interval between USs.

Conditioning began on Day 4 and lasted for eight daily sessions. Signal duration was $6 \mathrm{sec}$; US duration was $3 \mathrm{sec}$ of access to the hopper; and the interreinforcer interval was randomly chosen from a set of five values: $10,14,18,22$, and $26 \mathrm{sec}($ mean $=18 \mathrm{sec})$. The pigeons received 20 trials per session.

The animals were assigned to one of the following groups, differing in the duration of the adaptation period (in seconds) before the first trial of each session. These durations were $30(n=5), 300(n=4)$, or 3,000 $(n=6)$ sec. During this period, a subject remained in a box under the same conditions as during the intertrial interval. All the events were controlled and keypecks recorded by a DEC PDP-8A computer located in an adjacent room.

\section{RESULTS}

Results were analyzed using two dependent measures: (1) probability of at least one keypeck in a trial, and
(2) responses per minute. Because both measures yielded similar results, we used only the former, which was also used in our prior experiments (Papini \& Overmier, 1984, 1985).

Figure 1 shows the acquisition of the keypeck behavior by each group during the eight sessions of training. Acquisition speed suggests an orderly trend across the durations of the adaptation period: the longer this period, the faster the acquisition speed. An analysis of variance for unequal sample sizes indicated a significant difference among groups $[F(2,12)=12.31, p<.01]$ and between sessions $[F(7,84)=23.24, p<.01]$. Additionally, the groups $\times$ sessions interaction also reached a significant level $[F(14,84)=2.48, p<.02]$, thus allowing comparisons among groups in each training session. Pairwise comparisons showed that Group 30 performed significantly lower than either of the other groups in Sessions 3 through $8[t \mathrm{~s}(96) \geq 2.64$, ps < .01] and significantly lower than Group 3,000 in Session $2[t(96)=2.10$, $p<.05]$. Only one other pairwise comparison reached a significant level: Groups 300 and 3,000 differed from each other only in Session 2 [ $t(96)=2.21, p<.05]$.

Data were also analyzed in terms of the following acquisition criterion: three out of four successive trials with at least one keypeck (see Gibbon et al., 1980). Table 1 presents these results. The same trend already noted in Figure 1 is evident under this criterion: acquisition rate appears to have been an inverse function of the length of the adaptation period. The statistical analyses of the pairwise comparisons show no significant difference between Groups 300 and $3,000[t(12)=0.69, p>.20]$ but a significant difference between those two groups and Group $30[t(12)=2.20, p<.05]$. As usual with this

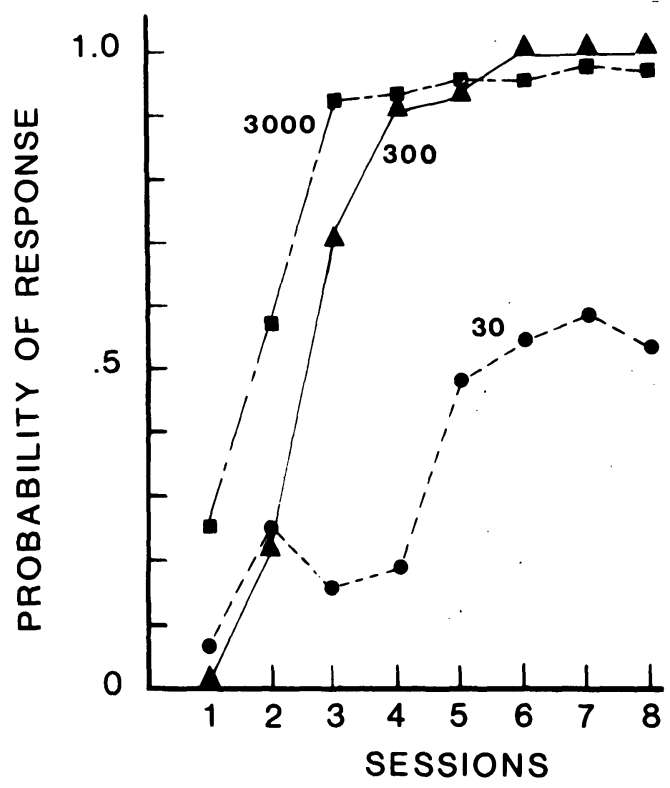

Figure 1. Probability of at least one response per trial during acquisition sessions for each group. Group labels refer to the duration (in seconds) of the adaptation period before the first trial of each session. $\bullet=30 ; \Delta=300 ; \boldsymbol{\Delta}=3,000$. 
Table 1

Number of Trials to Reach the Acquisition

\begin{tabular}{cccc}
\hline & $\begin{array}{c}\text { Group } 30 \\
n=5\end{array}$ & $\begin{array}{c}\text { Group } 300 \\
n=4\end{array}$ & $\begin{array}{c}\text { Group 3,000 } \\
n=6\end{array}$ \\
\hline & 12 & 41 & 20 \\
160 & 20 & 1 \\
& 82 & 63 & 12 \\
& 80 & 35 & 40 \\
& 32 & & 28 \\
Mean & 73.2 & 39.8 & 41 \\
\hline
\end{tabular}

Note-Acquisition criterion: three out of four successive trials with at least one keypeck (Gibbon et al., 1980).

acquisition criterion, data are characterized by a considerable amount of variability (Gibbon \& Balsam, 1981).

\section{DISCUSSION}

The results presented in this experiment suggest that the adaptation period before the start of daily conditioning trials does modulate acquisition rate of the pigeon's keypeck behavior in the autoshaping situation. The effect seems to be relatively larger for fairly short adaptation periods lasting from seconds to a few minutes. For relatively long ones, say between 5 and $50 \mathrm{~min}$, the effect is apparent only as a modest nonsignificant trend in group means. Yet it is in this latter range that the preconditioning adaptation effect was expected to be the largest, because that is where the impact on the $\mathrm{C} / \mathrm{T}$ ratio is greatest. This point is further illustrated in Table 2, in which the obtained reinforcements-tocriterion in each group are compared with the expected reinforcementsto-criterion using Gibbon and Balsam's (1981, Figure 7.2) regression fit and the average cycle (total session length divided by the number of USs) to compute the $\mathrm{C} / \mathrm{T}$ ratio. The expected reduction in reinforcements-to-criterion is greater for increases in adaptation periods from 300 to $3,000 \mathrm{sec}$ than from 30 to $300 \mathrm{sec}$, whereas the obtained reduction is greater for increases from 30 to $300 \mathrm{sec}$ than from 300 to $3,000 \mathrm{sec}$. The fact that the effect is not proportional to the increased presession period suggests that although the presession adaptation period plays some role, it does not do so by simply adding to the base for computing $\mathbf{C}$.

The markedly slower acquisition in Group 30 than in the other two groups-and those two not differing significantly-might be accounted for by assuming a more complex (i.e., nonlinear) function between acquisition speed and the $C / T$ ratio than Gibbon and Balsam (1981) suggested. Alternative assumptions, of course, do exist-some complex, some simple.

A complex alternative is that the pigeon "computes" the $\mathrm{C} / \mathrm{T}$ ratio in a way that weights recent intervals more heavily than earlier intervals (Killeen, 1981). Such an averaging rule would have the effect of attenuating the effects of the presession waits and thus attenuate differences between groups expected on the basis of overall $\mathrm{C} / \mathrm{T}$ ratios. If this were true, however, then the probability of pecking on a given trial should vary systematically within a session as the presession wait con-

Table 2

Expected and Obtained Reinforcements to Criterion

\begin{tabular}{cccc}
\hline \multirow{2}{*}{$\begin{array}{c}\text { Presession } \\
\text { Period }\end{array}$} & C/T Ratio & \multicolumn{2}{c}{ Reinforcements-to-Criterion } \\
\cline { 3 - 4 } & 3.10 & Expected & Obtained \\
\hline 30 & 5.35 & 101.96 & 73.2 \\
300 & 27.85 & 64.85 & 39.8 \\
3,000 & 16.51 & 23.7 \\
\hline
\end{tabular}

Note-The $\mathrm{C} / \mathrm{T}$ ratio includes the presession period. Acquisition criterion: Three out of four successive trials with at least one keypeck (Gibbon et al., 1980). Expected reinforcements-to-criterion were computed using values from Gibbon and Balsam's (1981) least squares regression $\left[n=260.6(C / T)^{-.8294}\right]$. tributes less and less. This effect should be largest for Group 3,000, for which the $\mathrm{C} / \mathrm{T}$ ratio, and hence the probability of a peck, should be declining. To address this possibility, we computed the probability of pecking during Trials 1-5 versus Trials $16-20$ for Sessions 3 and 8 for Group 3,000. We found that the probability of pecking increased from Trials 1-5 to Trials 16-20 on both Session 3 (.77 to .97) and Session $8(.83$ to 1.0$)$. Other samples confirmed this pattern. Thus the present data do not lend support to the differential averaging hypothesis as an account of our data. A simple alternative explanation is that the preconditioning period may contribute to acquisition only by allowing the defensive posthandling effects to dissipate. These defensive effects may require more than $30 \mathrm{sec}$ but less than $5 \mathrm{~min}$ to do so; if so, then waits longer than $5 \mathrm{~min}$ would contribute nothing to acquisition. This is consistent with our present data.

On the basis of these results, it is not clear that the trials-per-session effect reported by Papini and Overmier (1984) can be attributed to relative differences in contextual expectancy levels produced by the adaptation period introduced at the start of each session. The present results, along with those of Jenkins et al. (1981), suggest that computation of $C$ is not started as soon as the animal is placed into the conditioning box and does not include the full preconditioning period on an equal basis; on the other hand, the preconditioning period is not irrelevant. This result supports our previous claim (Papini \& Overmier, 1985) that the expectancy ratio (Gibbon \& Balsam, 1981) provides at best an incomplete description of the acquisition process.

The present results contribute to a growing body of evidence (Durlach, 1983; Kaplan, 1985), based upon manipulations of contextual expectancy, that fail to support the SET theory of conditioning.

\section{REFERENCES}

Balsam, P. (1984). Relative time in trace conditioning. Annals of the New York Academy of Sciences, 423, 211-227.

Balsam, P. (1985). The functions of context in learning and performance. In P. Balsam \& A. Tomie (Eds.), Context and learning (pp. 1-21). Hillsdale, NJ: Erlbaum.

DURLACH, P. J. (1983). The effect of signalling intertrial unconditioned stimuli in autoshaping. Journal of Experimental Psychology: Animal Behavior Processes, 9, 374-389.

Gibbon, J., \& Balsam, P. (1981). Spreading association in time. In C. M. Locurto, H. S. Terrace, \& J. Gibbon (Eds.), Autoshaping and conditioning theory (pp. 219-253). New York: Academic Press.

Gibbon, J., Farrell, L., Locurto, C. M., Duncan, H. J., \& TerRACE, H. S. (1980). Partial reinforcement in autoshaping with pigeons. Journal of Experimental Psychology: Animal Behavior Processes, 11, 172-193.

Jenkins, H. M., BARnes, R. A., \& Barrera, F. J. (1981). Why autoshaping depends on trial spacing. In C. M. Locurto, H. S. Terrace, \& J. Gibbon (Eds.), Autoshaping and conditioning theory (pp. 255284). New York: Academic Press.

KAPLAN, P. S. (1985). Explaining the effects of relative time in trace conditioning: A preliminary test of a comparator hypothesis. Animal Learning \& Behavior, 13, 233-238.

KILleEN, P. R. (1981). Averaging theory. In C. M. Bradshaw, E. Szabadi, \& C. F. Lowe (Eds.), Quantification of steady state operant behavior (pp. 21-34). Amsterdam: Elsevier-North Holland.

PaPinI, M. R., \& OVermier, J. B. (1984). Autoshaping in pigeons: Effects of partial reinforcement on acquisition and extinction. Interamerican Journal of Psychology, 18, 75-86.

PAPINI, M. R., \& Overmier, J. B. (1985). Partial reinforcement and autoshaping of the pigeon's key-peck behavior. Learning \& Motivation, 16, 109-123.

ROBERTS, S., \& HolDER, M. D. (1984). What starts an internal clock? Journal of Experimental Psychology: Animal Behavior Processes, 10, 273-296.

RoBerTs, S., \& HolDER, M. D. (1985). Effect of classical conditioning on an internal clock. Journal of Experimental Psychology: Animal Behavior Processes, 11, 194-214.

(Manuscript received for publication March 14, 1987.) 